\title{
Placental thickness and its correlation with estimated foetal weight: a cross-sectional study in a tertiary care centre in South India
}

\author{
Goldy S. J. ${ }^{*}$, Sheba Rosatte Victor ${ }^{2}$, Bewin Oral J. ${ }^{3}$, Adaline Thangam ${ }^{1}$, \\ Usha Christopher ${ }^{1}$, Adlin Rose ${ }^{1}$
}

\begin{abstract}
${ }^{1}$ Department of Obstetrics and Gynecology, Dr. Somervell Memorial CSI Medical College and Hospital, Karakonam, Kerala, India

${ }^{2}$ Department of Obstetrics and Gynecology, Tirunelveli Medical College Hospital, Tirunelveli, Tamil Nadu, India

${ }^{3}$ Department of Microbiology, Dr. Somervell Memorial CSI Medical College and Hospital, Karakonam, Kerala, India
\end{abstract}

Received: 22 February 2019

Accepted: 05 March 2019

\author{
*Correspondence: \\ Dr. Goldy S. J., \\ E-mail: goldybewin@gmail.com
}

Copyright: (c) the author(s), publisher and licensee Medip Academy. This is an open-access article distributed under the terms of the Creative Commons Attribution Non-Commercial License, which permits unrestricted non-commercial use, distribution, and reproduction in any medium, provided the original work is properly cited.

\begin{abstract}
Background: The placenta is a multifaceted organ which modulates and modifies the maternal environment resulting in foetal development. It could be assumed that a healthy placenta culminates in a healthy foetus. Hence the morphometric analysis of a placenta during sonogram is inevitable. The aim of the study was to estimate the relationship between placental thickness and estimated foetal weight.

Methods: The study was a cross-sectional study and included 450 antenatal women attending the department of Obstetrics and Gynaecology, Tirunelveli Medical College from May 2013 to May 2014. These women had regular cycles with a known Last menstrual period and a singleton foetus. After ethics committee approval, meticulous history including age, parity, demographic factors and past history were recorded. After obtaining consent, these women underwent placental thickness measurement between 14-40 weeks of pregnancy.

Results: In the study mean placental thickness between the ranges of $11-49 \mathrm{~mm}$ was $28.7 \mathrm{~mm}$ and mean estimated foetal weight was 1.421 kilogram. The correlation between the two was 0.943 . Hence the positive correlation between the placental thickness and foetal weight is confirmed ( $\mathrm{p}$ value $<0.001$ ).

Conclusions: Determining the estimated foetal weight is an important reason for doing a sonogram, especially in third trimester. Placental thickness measured at the level of umbilical cord insertion can serve as an additional parameter in estimating foetal weight in addition to the foetal parameters, since there is a linear correlation between placental thickness and foetal weight.
\end{abstract}

Keywords: Estimated foetal weight, Placenta, Placental thickness, Umbilical cord insertion, Ultrasonogram

\section{INTRODUCTION}

The placenta plays a pivotal role in supplying oxygen and nutrients to the foetus.

An intact uteroplacental unit is essential for providing the substrates for the growth of the foetus in utero. ${ }^{1}$ One of the hormones produced by the placenta is the growth hormone-like Somatomammotropin. It can be inferred that an appropriate placental growth culminates in a healthy baby. Impaired placental development may adversely affect the foetal growth and development. Antenatal assessment of foetal weight helps in forecasting the neonatal outcome. 
Both large for gestational age and small for gestational age babies contribute to a major proportion of neonatal intensive care admissions.

Foetal growth parameters such as biparietal diameter, head circumference, femur length and abdominal circumference are used in the sonographic estimation of gestational age and foetal weight of foetus in the second and third trimesters. Foetal weight can be estimated by Sherpard's formula using only Biparietal diameter and abdominal circumference with a deviation of 295 grams from the actual weight. These growth parameters are adversely affected by insufficient nutrients reaching the foetus through placenta. In these foetuses the placenta is usually thin. There must be a certain relationship between the placental thickness and the growth parameters ${ }^{2}$. Hence the study aims at identifying the correlation between placental thickness and estimated foetal weight.

Sonography helps us determine the estimated foetal weight and the placental size. Placental location, placental maturity and retroplacental translucent zone are routinely reported by any sonographer. Placental thickness is an important parameter which is often overlooked by the sonologist. Abnormal placental thickness is associated with poor neonatal outcome. But very few studies have proved the correlation between placental thickness and foetal weight. The aim of the study is to determine the normal placental thickness from 14 weeks onwards and to find out the correlation between placental thickness and estimated foetal weight.

\section{METHODS}

The present study was a cross-sectional study and was conducted in the Department of Obstetrics and Gynaecology in collaboration with the Department of Radiology, Tirunelveli Medical College Hospital. A total of 450 antenatal women of any age were enrolled in the study from May 2013 to May 2014.

Written informed consent was obtained from these women after they were explained in detail about the investigation. The study was approved by the Institutional Ethics Committee. All recruited women were examined clinically and the demographic profile and clinical data like age, parity, past obstetric history and past medical events were recorded. These women underwent measurement of placental thickness between 14-40 weeks of gestation.

\section{Inclusion criteria}

Normal antenatal women in all gestational ages between 14-40 weeks were included in the study with:

- A known last menstrual period

- Singleton uncomplicated pregnancy

- Prior regular cycles.

\section{Exclusion criteria}

- Women with irregular cycles

- Women who were on Oral Contraceptive pills in the prior 3 months

- Pregnancies complicated with gestational hypertension, diabetes, twins. hydrops, foetal growth restriction and congenital anomalies.

- Placenta with morphological variations like bilobed placenta, succenturiate placenta, circumvallate placenta and placenta membranaceae were excluded.

- Placenta with variable cord insertions like battledore placenta, velamentous placenta were excluded.

- Placenta with poor visualisation of cord insertion were excluded.

- Placenta with poor sonographic visualisation were excluded.

- Pregnancies complicated by vaginal bleeding both in the early and late pregnancy.

- Pregnancies complicated by anaemia, cardiac disorders and uterine anomalies.

- Women with morbid obesity were excluded from the study.

- Women with genetic abnormalities were excluded

- Women with sickle cell disease and thalassemia were excluded from the study.

\section{Technique of measuring placental thickness}

All antenatal women were subjected to sonogram using the Larson and Turbo Sequina model with a convex probe with a frequency of $2-5 \mathrm{MHZ}$.

The placenta was scanned with a moderately distended bladder in supine position. The transducer is placed on the maternal abdomen after applying coupling agent. The transducer is placed perpendicular to both chorionic and basal plate as a tangential measurement would distort the placental thickness. The placental thickness in millimetre is measured at the cord insertion site. All these measurements were done by a single examiner to avoid observer bias. All the patients were explained about the study before the examination. Consent was obtained. While measuring the placental thickness, care was taken to avoid the myometrium and the retroplacental complex.

\section{Cord insertion site}

The site is usually central but slightly eccentric insertion is acceptable. The sonographic appearance of the cord insertion appears either as hypoehoic areas closest to the chorionic plate in the thickest portion of the placenta with a $v$ shape or as linear echoes emanating at right angles from the placental surface. Placental thickness is calculated from the echogenic chorionic plate and the placental myometrial interface near the mid placental portion. ${ }^{3}$ The myometrium and the sub placental veins are excluded from the measurement. All measurements were taken in a relaxed uterus since a uterine contraction 
would cause spurious thickening of the placenta. Placental thickness depends on the placental size, foetal and maternal blood. The placental thickness increases during contraction because the intervillous space becomes distended with maternal blood.

\section{Placental myometrial interface}

Correct identification of the placental myometrial interface is required for accurate measurement of placental thickness. Focal myometrial thickening due to myoma or contractions may spuriously suggest placental thickening but attention to the placental myometrial echogenicity difference should see to that the placenta drapes over the regions of myometrial thickening. Placental thickness measured sonographically was correlated with foetal parameters such as biparietal diameter (BPD), femur length (FL), head circumference (HC) and abdominal circumference (AC). Placental thickness was also correlated with the estimated foetal weight which was derived from the foetal parameters.

\section{Statistical analysis}

The study subjects namely the pregnant women were described the categorical variables and described in terms of percentages and the continuous variables had been described in terms of averages. The relationship between variables were analysed and interpreted by students t test for two groups of variables and ANOVA for more than two groups of variables.

The association between the attributes were identified by Chi square. Regression equations were developed to estimate the estimated foetal weight and other parameters through placental thickness as an estimator. The statistical package IBM SPSS statistics-20 was used for the above statistical purposes. The $\mathrm{p}$ value $<0.05$ were considered as statistically significant in tow tailed.

\section{RESULTS}

In this study, the mean age of the total mothers was $26 \pm 4.1$ years. The mean age of primiparous mothers was $26.1 \pm 3.9$ years. The mean age of multiparous mothers was $26.4 \pm 4.3$ years (Table 1 ).

Among the 450 mothers $293(65.1 \%)$ were primiparous. Rest were multiparous 157 (34.9\%). Among the 450 mothers 10 were teen age mothers $(2.2 \%)$. Majority of the women were in 25-29 years (190 mothers- $42.2 \%)$. (Table 2).

Table 1: Comparison of age between parity of mothers.

\begin{tabular}{|c|c|c|c|c|c|c|c|}
\hline \multirow{2}{*}{ Parity } & \multirow{2}{*}{$\mathbf{N}$} & \multicolumn{2}{|l|}{ Age } & \multirow{2}{*}{ Difference $b / w$ means } & \multirow[b]{2}{*}{$\mathrm{t}$} & \multirow{2}{*}{ df } & \multirow{2}{*}{ Significance } \\
\hline & & Mean & SD & & & & \\
\hline Primi & 293 & 26.1 & 3.9 & \multirow{3}{*}{0.3} & \multirow{3}{*}{0.809} & \multirow{3}{*}{498} & \multirow{3}{*}{$\mathrm{P}=0.419$} \\
\hline Multi & 157 & 26.4 & 4.3 & & & & \\
\hline Total & 450 & 26.2 & 4.1 & & & & \\
\hline
\end{tabular}

Table 2: Age wise percentage distribution of parity.

\begin{tabular}{|l|l|l|l|l|l|l|}
\hline Age group & Primi & $\mathbf{N}$ & $\mathbf{\%}$ & $\mathbf{N}$ & $\mathbf{\%}$ & $\mathbf{N}$ \\
\hline$<20$ & 6 & 2.0 & 4 & 2.5 & 10 & 2.2 \\
\hline $20-24$ & 103 & 35.2 & 53 & 33.8 & 156 & 34.7 \\
\hline $25-29$ & 125 & 42.7 & 65 & 41.4 & 190 & 42.2 \\
\hline $30-34$ & 52 & 17.7 & 26 & 16.6 & 78 & 17.3 \\
\hline $35-39$ & 7 & 2.4 & 9 & 5.7 & 16 & 3.6 \\
\hline Total & 293 & 100.0 & 157 & 100.0 & 450 & 100.0 \\
\hline
\end{tabular}

Table 3: Relation between age of mother with placental thickness.

\begin{tabular}{|c|c|c|c|c|c|c|}
\hline \multirow{2}{*}{ Age group (years) } & \multirow{2}{*}{$\mathbf{N}$} & \multicolumn{2}{|c|}{ Placental Thickness } & \multirow{2}{*}{ ANOVA F } & \multirow{2}{*}{ Significance } & \multirow{2}{*}{$\begin{array}{l}\text { Comparison of } \\
\text { significance }\end{array}$} \\
\hline & & Mean & SD & & & \\
\hline$<20$ & 10 & 28.0 & 7.4 & \multirow{5}{*}{0.301} & \multirow{5}{*}{$\mathrm{P}=0.877$} & \multirow{5}{*}{ Nil } \\
\hline $20-24$ & 156 & 29.1 & 7.3 & & & \\
\hline $25-29$ & 190 & 28.4 & 7.5 & & & \\
\hline $30-34$ & 78 & 29.1 & 8.0 & & & \\
\hline $35-39$ & 16 & 28.1 & 7.6 & & & \\
\hline Total & 450 & 28.7 & 7.5 & & & \\
\hline
\end{tabular}


Table 4: Relation between parity of mother with placental thickness.

\begin{tabular}{|l|l|l|l|l|l|l|l|}
\hline \multirow{2}{*}{ Parity } & n & Placental thickness & Difference b/w means & t & df & Significance \\
\hline Primi & 293 & 28.6 & 7.5 & & & \\
\hline Multi & 157 & 29.0 & 7.5 & 0.4 & 0.492 & 448 & P=0.623 \\
\hline Total & 450 & 28.7 & 7.5 & & & \\
\hline
\end{tabular}

Table 5: Relation between estimated weights of foetus with placental thickness.

\begin{tabular}{|c|c|c|c|c|c|c|}
\hline \multirow{2}{*}{ Estimated weight } & \multirow{2}{*}{$\mathbf{N}$} & \multicolumn{2}{|c|}{ Placental thickness } & \multirow{2}{*}{ ANOVA F } & \multirow{2}{*}{ Significance } & \multirow{2}{*}{$\begin{array}{l}\text { Comparison of } \\
\text { significance }\end{array}$} \\
\hline & & Mean & SD & & & \\
\hline$<500$ & 128 & 19.8 & 2.8 & \multirow{7}{*}{582.766} & \multirow{7}{*}{$\mathrm{P}<0.001$} & \multirow{7}{*}{ All are significant } \\
\hline $500-1000$ & 79 & 25.0 & 2.8 & & & \\
\hline $1000-1500$ & 39 & 29.5 & 1.9 & & & \\
\hline $1500-2000$ & 45 & 32.0 & 2.2 & & & \\
\hline $2000-2500$ & 68 & 34.9 & 1.6 & & & \\
\hline $2500-3000$ & 65 & 37.4 & 2.6 & & & \\
\hline $3000-3500$ & 26 & 39.8 & 2.6 & & & \\
\hline Total & 450 & 28.7 & 7.5 & & & \\
\hline
\end{tabular}

The estimates such as age, parity and estimated weight of the foetus were correlated with the estimator placental thickness. There was no statistically significant relationship between age of the mother and placental thickness $\mathrm{p}>0.05$ (Table 3 ).

There was no statistically significant relationship between the parity of the mother and placental thickness $\mathrm{p}>0.05$ (Table 4).

The relationship between the mean placental thickness and the estimated foetal weight were statistically very highly significant $\mathrm{p}>0.001$ (Table 5).

The calculated foetal weight has a significant positive correlation with placental thickness. The mean placental thickness for a foetal weight of 500 grams to $1 \mathrm{~kg}$ was $25 \mathrm{~mm}$. The mean placental thickness for a foetal weight of $1 \mathrm{~kg}$ to $1.5 \mathrm{~kg}$ was $29.5 \mathrm{~mm}$. The mean placental thickness for a foetal weight of 1.5 to $2 \mathrm{~kg}$ was $32 \mathrm{~mm}$. The mean placental thickness for a foetal weight of 2 $2.5 \mathrm{~kg}$ was $34.9 \mathrm{~mm}$. The mean placental thickness for a foetal weight of $2.5-3 \mathrm{~kg}$ was $37.4 \mathrm{~mm}$. The mean placental thickness for a foetal weight of $3-3.5 \mathrm{~kg}$ was $39.8 \mathrm{~mm}$ (Table 5).

The mean placental thickness was $28.7 \mathrm{~mm}$ (Table 6).

Placental thickness has a significant positive correlation with foetal weight with $\mathrm{R}$ value of 0.943 .

Placental thickness positively correlates with Biparietal diameter with $\mathrm{R}$ value of 0.948 .
Placental thickness positively correlates with Femur length with $\mathrm{R}$ value of 0.951 .

Placental thickness positively correlates with abdominal circumference with $\mathrm{R}$ value of 0.957 .

Placental thickness positively correlates with Head circumference with $\mathrm{R}$ value of 0.948 .

All these correlation coefficients were statistically very highly significant $(\mathrm{p}<0.001)$ (Table 7).

Placental thickness has a linear correlation with estimated foetal weight (Figure 1).

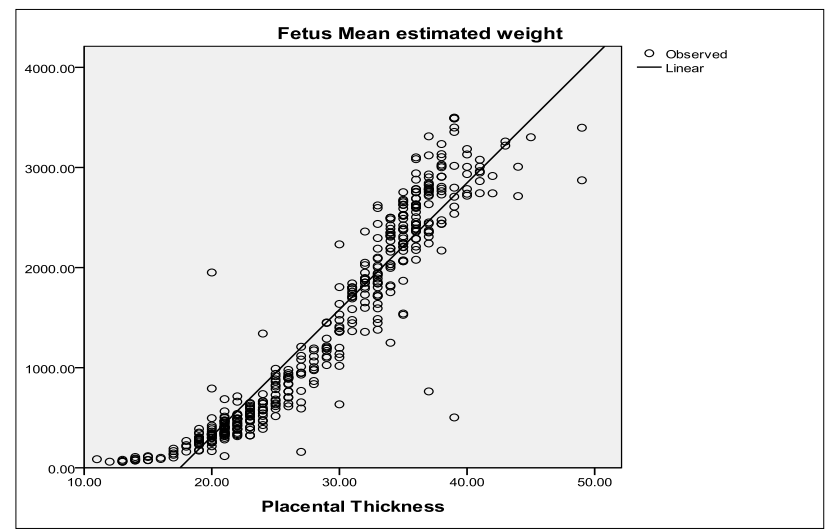

$\mathrm{Y}=126.6, \mathrm{X}=2216.745$

Figure 1: Regression equation for foetal mean estimated weight (Y) on placental thickness (X). 
Table 6: LMP weeks with placental thickness and estimated foetal weight.

\begin{tabular}{|c|c|c|c|c|c|}
\hline \multirow{2}{*}{ LMP GA weeks } & \multicolumn{3}{|c|}{ Placental thickness } & \multicolumn{2}{|c|}{ Estimated foetal weight } \\
\hline & $\mathbf{N}$ & Mean & SD & Mean & SD \\
\hline 14.00 & 6 & 13.0 & 1.4 & 70.7 & 9.8 \\
\hline 15.00 & 5 & 14.6 & 1.3 & 89.2 & 7.4 \\
\hline 16.00 & 6 & 15.3 & 1.4 & 101.8 & 21.3 \\
\hline 17.00 & 1 & 15.0 & 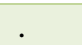 & 108.0 & \\
\hline 17.50 & 1 & 17.0 & . & 143.0 & \\
\hline 18.00 & 3 & 19.3 & 2.1 & 150.3 & 28.9 \\
\hline 18.50 & 1 & 18.0 & & 162.0 & \\
\hline 19.00 & 15 & 19.7 & 2.1 & 248.0 & 49.3 \\
\hline 19.50 & 1 & 21.0 & & 299.0 & \\
\hline 20.00 & 19 & 20.3 & 1.4 & 309.3 & 58.8 \\
\hline 20.50 & 7 & 21.0 & 1.3 & 359.1 & 79.8 \\
\hline 21.00 & 7 & 19.9 & 1.1 & 326.3 & 31.6 \\
\hline 21.50 & 3 & 21.3 & 0.6 & 390.0 & 32.0 \\
\hline 22.00 & 22 & 21.2 & 1.5 & 393.5 & 94.0 \\
\hline 22.50 & 5 & 21.8 & 1.3 & 412.4 & 40.6 \\
\hline 23.00 & 25 & 22.3 & 1.1 & 468.6 & 63.9 \\
\hline 23.50 & 5 & 22.8 & 1.8 & 520.2 & 51.5 \\
\hline 24.00 & 27 & 23.3 & 1.6 & 579.9 & 75.6 \\
\hline 24.50 & 2 & 32.0 & 9.9 & 568.5 & 92.6 \\
\hline 25.00 & 10 & 24.4 & 1.6 & 679.5 & 69.0 \\
\hline 25.50 & 1 & 27.0 & & 654.0 & \\
\hline 26.00 & 10 & 26.0 & 4.3 & 767.0 & 111.2 \\
\hline 27.00 & 10 & 25.9 & 2.2 & 820.6 & 145.3 \\
\hline 27.50 & 2 & 25.5 & 0.7 & 902.5 & 17.7 \\
\hline 28.00 & 15 & 27.0 & 1.5 & 1001.7 & 91.2 \\
\hline 29.00 & 9 & 28.9 & 0.9 & 1066.7 & 187.1 \\
\hline 29.50 & 2 & 29.0 & 0.0 & 1151.0 & 73.5 \\
\hline 30.00 & 8 & 29.2 & 2.2 & 1194.4 & 101.3 \\
\hline 30.50 & 2 & 29.5 & 0.7 & 1302.0 & 155.6 \\
\hline 31.00 & 10 & 29.7 & 2.3 & 1434.4 & 95.3 \\
\hline 31.50 & 6 & 31.3 & 1.0 & 1525.5 & 134.2 \\
\hline 32.00 & 19 & 32.5 & 1.4 & 1659.3 & 125.2 \\
\hline 32.50 & 1 & 31.0 & & 1692.0 & . \\
\hline 33.00 & 11 & 32.5 & 1.4 & 1894.1 & 165.0 \\
\hline 33.50 & 3 & 32.7 & 1.2 & 1956.0 & 127.4 \\
\hline 34.00 & 22 & 32.9 & 3.3 & 2014.4 & 143.2 \\
\hline 34.50 & 2 & 35.5 & 3.5 & 2086.5 & 118.1 \\
\hline 35.00 & 33 & 34.4 & 3.3 & 2254.8 & 397.9 \\
\hline 35.50 & 8 & 35.2 & 0.5 & 2331.5 & 144.9 \\
\hline 36.00 & 44 & 35.8 & 1.6 & 2556.2 & 150.9 \\
\hline 36.50 & 5 & 39.2 & 3.1 & 2756.8 & 63.8 \\
\hline 37.00 & 18 & 37.8 & 1.9 & 2805.3 & 161.1 \\
\hline 37.50 & 5 & 40.2 & 5.2 & 2849.6 & 45.9 \\
\hline 38.00 & 23 & 39.3 & 2.9 & 3028.0 & 184.8 \\
\hline 38.50 & 4 & 40.5 & 3.1 & 3247.0 & 130.2 \\
\hline 39.00 & 2 & 43.0 & 0.0 & 3238.5 & 28.9 \\
\hline 39.50 & 2 & 39.0 & 0.0 & 3493.5 & 6.4 \\
\hline 40.00 & 1 & 39.0 & & 3492.0 & \\
\hline Total & 450 & 28.7 & 7.5 & 1421.9 & 1008.4 \\
\hline
\end{tabular}


Table 7: Regression equations between estimator with estimating parameter.

\begin{tabular}{|l|l|l|l|l|}
\hline Estimator parameter X & Estimating parameters $\mathbf{~}$ & $\mathbf{R}$ & $\mathbf{R}^{2}$ & Regression equations Y on X \\
\hline Placental & GA LMP & 0.951 & 0.905 & Y=3.776+0.951 X \\
\hline Placental & GA USG & 0.959 & 0.919 & Y=1.801+0.959 X \\
\hline Placental & Est. Mean Weight & 0.943 & 0.888 & Y=126.6 X-2216.745 \\
\hline Placental & AFI & 0.163 & 0.026 & Y=13.794-0.56 X \\
\hline Placental & BPD & 0.948 & 0.899 & Y=2.444 x-2.592 \\
\hline Placental & FL & 0.951 & 0.904 & Y=2.246 x-13.138 \\
\hline Placental & AC & 0.957 & 0.916 & Y=9.977 x-49.335 \\
\hline Placental & HC & 0.948 & 0.899 & Y=8.726 x+0.022 \\
\hline
\end{tabular}

\section{DISCUSSION}

During the early stages of placental development, the placenta envelops the embryo, as a shell of trophoblast begins to invade the uterine stroma. The yolk sac placenta which is in the coelomic cavity is connected to the embryonic cavity via vitelline stalk and its vessels. This is a transient structure which is replaced by chorioallantoic placenta.

The allantoic stroma and embryonic blood vessels grow into chorionic plate to become chorioallantoic placenta. Foetal blood vessels grow into the developing villi to become the chorionic villi tree. The chorioallantoic placenta surrounds the embryo. By 9-12 weeks, two thirds of it regress to form the smooth chorion laevae and remaining one third which persists is attached to the umbilical cord to become the true placenta (chorion frondosum). ${ }^{4}$ By 12 weeks placenta attains a grey granular appearance. Placenta is supplied by the spiral arteries. From 12 weeks to term, the placenta grows at a variable rate to cope up with the growth of the foetal size. Due to continuous foetal growth and expansion, placenta also enlarges. The increase in surface area is parallel to the uterine expansion. The placenta occupies $15-30 \%$ of the inner surface of the uterus. The maternal aspect of the placenta is formed by the basal plate. The foetal aspect is formed by the chorionic plate and the amniotic membrane. In between the two is the intervillous space containing the stem villi filled with maternal blood. The amniotic membrane is a thin membrane loosely attached to the chorionic plate which is an ectodermal derivative. It has no role in the development of the placenta.

At term the placenta is $3-4 \mathrm{~cm}$ thick and $15-25 \mathrm{~cm}$ in diameter. The word placenta is derived from the Greek word 'platuos' meaning a flat cake, which exactly describes its appearance. In the term placenta, the syncitiotrophoblast thins out at areas overlying the foetal capillaries and thickens at areas overlying the endoplasmic reticulum. ${ }^{5}$ The former is the area of exchange and the latter is the area of synthesis. The cytotrophoblast becomes sparse and the basement membrane becomes thicker. The stroma contains dilated vessels with few hofbaeur cells containing $\operatorname{IgG}$ surface receptors. 80-100 spiral arteries pierce the decidual plate and enter the intervillous spaces. The spiral artery has a narrow lumen; hence the intervillous pressure is high. This high pressure forces the blood into the intervillous spaces and supplies the entire villous tree with oxygenated blood. With a decline in pressure, the blood flows back from the chorionic plate to the decidua entering the endometrial veins thus reaching the maternal system. The total blood in all the intervillous spaces of the placenta is about $150 \mathrm{ml}$. The entire volume of blood is replaced 3-4 times per minute. Placental exchange occurs only where the foetal vessels are in intimate contact with the syncytial membrane. The syncytium contains a brush border containing numerous microvilli which increase the surface area and the exchange is enhanced. The placental membrane which was thick initially $0.025 \mathrm{~mm}$ thick begins to thin out from the fourth month of gestation and becomes $0.002 \mathrm{~mm}$ later on. In the later part of the pregnancy, the foetal vessels are very intimate to the syncytium thus facilitating greater exchange. 6

Human placenta is haemochorial because the maternal blood in the intervillous system is separated from the foetal system by a membrane of the chorionic derivative. ${ }^{7}$ It could be summarised that the human placental complex is the product of the co-operative effort of the extra embryonic tissues of the embryo and the uterine tissue.

The placenta grows by multiplication and ramification of the chorionic villi. The quantum of growth could be assessed by measuring the placental thickness or by volumetric assay. ${ }^{8}$ But the problem with volumetric assay is that it is too tedious to be done on a regular basis. The placenta grows throughout pregnancy, the initial growth superseding the foetal growth and later on plateaus as the foetus reaches term. Hence the growth rate of the placenta is directly proportional to the foetal growth rate in early gestation. Later on, the ratio of foetal weight to placental weight increases.

Thin placenta less than $2.5 \mathrm{~cm}$ thickness is seen in association with foetal growth restriction, small for dates, foetal malformations, foetal trisomy especially trisomy 18, chronic intrauterine infections, gestational hypertension, maternal pregestational diabetes, maternal and foetal polycythemia and placenta membranaceae. ${ }^{9}$ 
Thick placenta $>4 \mathrm{~cm}$ is associated with gestational diabetes, hydrops foetalis, intrauterine infections, foetal macrosomia and Beckwith-Weidmann syndrome. ${ }^{10}$ At times it can occur as a normal variation. Congenital syphilis, Congenital foetal nephrosis, placental chorioangioma, large intervillous thrombi and villous oedema can result in a thick placenta.

Ultrasound is a shadow of a modern obstetrician. The ultrasound measurement of the placental thickness, at the cord insertion site is very simple and clinically useful. It helps in evaluating and detecting certain placental abnormalities that significantly impact the management and outcome of pregnancies. Early detection of any pathology in the placental bed and villi helps obstetrician to consider prenatal care precisely.

In present study, the placental thickness increases with advancing gestational age. The foetal weight positively correlated with increase in placental thickness as $\mathrm{p}<0.001$ which is very much statistically significant. Inspite of meticulous clinical examination and obtaining multiple sononographic foetal growth parameters, many of the low birth weight infants are not diagnosed till birth. It is known that the estimated weight prediction is erroneous in both extremities of weight. Hence additional parameters like placental thickness can help in estimating foetal weight.

In present study, the estimated foetal weight was calculated using the foetal parameters like BPD, FL, AC and HC. The calculated foetal weight has a significant positive correlation with placental thickness. The mean placental thickness for a foetal weight of 500 grams to $1 \mathrm{~kg}$ was $25 \mathrm{~mm}$. The mean placental thickness for a foetal weight of $1 \mathrm{~kg}$ to $1.5 \mathrm{~kg}$ was $29.5 \mathrm{~mm}$. The mean placental thickness for a foetal weight of 1.5 to $2 \mathrm{~kg}$ was $32 \mathrm{~mm}$. The mean placental thickness for a foetal weight of 2$2.5 \mathrm{~kg}$ was $34.9 \mathrm{~mm}$. The mean placental thickness for a foetal weight of $2.5-3 \mathrm{~kg}$ was $37.4 \mathrm{~mm}$. The mean placental thickness for a foetal weight of $3-3.5 \mathrm{~kg}$ was $39.8 \mathrm{~mm}$.

Placental thickness has a significant positive correlation with foetal weight with $\mathrm{R}$ value of 0.943 . This is in accordance with the study of Afrakheth et al, Moein et al and Balla et al. ${ }^{11,12}$ According to Afraketh et al and Moein et al, birth weight had a positive relation to placental thickness in second and third trimesters but could not predict low birth weight babies.

Placental thickness positively correlates with Biparietal diameter with $\mathrm{R}$ value of 0.9948 . Placental thickness increases as BPD increases. Hence placental thickness can be used as a sonological parameter instead of biparietal diameter in estimating foetal weight (when there is difficulty in measuring the foetal head-abnormal foetal head, abnormal foetal position and hydrocephalus). ${ }^{13}$ Placental thickness positively correlates with Femur length with $\mathrm{R}$ value of 0.951 . Placental thickness increases as the femur length increases. Hence placental thickness can be used as a sonological parameter for estimating foetal weight instead of femur length. ${ }^{14}$ (In conditions where femur length is erroneousAchondroplasia and other bony deformities).

Placental thickness positively correlates with abdominal circumference with $\mathrm{R}$ value of 0.957 . Placental thickness increases as the abdominal circumference increases. Hence Placental thickness could be used to estimate foetal weight when there is sonographic difficulty in measuring abdominal circumference. Placental thickness positively correlates with Head circumference with $\mathrm{R}$ value of 0.948 . All these correlation coefficients were statistically very highly significant $(\mathrm{p}<0.001)$. Regression equations were also derived between estimators with estimating parameters. Hence a linear correlation between placental thickness and estimated foetal weight is proved.

\section{CONCLUSION}

There is a significant positive correlation between placental thickness and the foetal growth parameters (biparietal diameter, femur length, abdominal circumference, head circumference). Likewise, there is a significant positive correlation between placental thickness and estimated foetal weight. It seems that using cut-off points for placental thickness can help obstetricians to predict new born birth weight and identify the foetus in danger of being low birth weight. Measurement of placental thickness should therefore be carried out routinely during obstetrics ultrasound scan.

\section{ACKNOWLEDGMENTS}

Authors would like to thank all the faculty and staff of the Department of Obstetrics and Gynaecology.

\section{Funding: No funding sources \\ Conflict of interest: None declared \\ Ethical approval: The study was approved by the Institutional Ethics Committee}

\section{REFERENCES}

1. Burton GJ, Woods AW, Jauniaux E, Kingdom JC. Rheological and physiological consequences of conversion of the maternal spiral arteries for uteroplacental blood flow during human pregnancy. Placenta. 2009;30:473-82.

2. Ohagwu CC, Abu PO, Ezeokeke UO, Ugwu AC. Relationship between placental thickness and growth parameters in normal Nigerian foetus. Afr $\mathbf{J}$ Biotechnol. 2009;8(2):133-8.

3. Smith NC, Smith APM. Obstetric and gynecological ultrasound made easy. $2^{\text {nd }}$ ed. Elsevier, London; 2006:123.

4. Moore KL. The placenta. In: Moore KL, Persaud TVN, eds. The developing human: Clinically 
oriented embryology. $7^{\text {th }}$ ed. WB Saunders: Philadelphia; 1993:110-118.

5. Ellery PM, Cindrova-Davies $\mathrm{T}$, Jauniaux $\mathrm{E}$, Ferguson-Smith AC, Burton GJS. Evidence for transcriptional activity in the syncytiotrophoblast of the human placenta. Placenta. 2009;30:329-34.

6. Bauer MK, Harding JE, Bassett NS, Breier BH, Oliver $\mathrm{MH}$, Gallaher $\mathrm{BH}$, et al. Fetal growth and placental function. Mol Cell Endocrinol. 1998;140:115-20.

7. Faber JJ, Thornburg KL. Placental Physiology: Structure and Function of Fetomaternal Exchange. New York, Raven Press, 1983.

8. Hafner E, Metzenbauer M, Ho“finger D, Stonek F, Schuchter K, Waldhör T, et al. Comparison between three-dimensional placental volume at 12 weeks and uterine artery impedance/notching at 22 weeks in screening for pregnancy-induced hypertension, preeclampsia and foetal growth restriction in a low-risk population. Ultrasound Obstet Gynecol. 2006;27:652-7.

9. Kliman HJ. Behind every healthy baby is a healthy placenta. In: Berman MR, ed. Parenthood Lost. Westport, CT: Bergin and Garvey; 2001:130-131.

10. Elchalal U, Ezra Y, Levi Y, Bar-Oz B, Yanai N, Intrator $\mathrm{O}$, et al. Sonographically thick placenta: a marker for increased perinatal risk-a prospective cross-sectional study. Placenta. 2000;21:268-72.
11. Afrakhteh M, Moeini A, Taheri MS, Haghighatkhah HR. Correlation between placental thickness in the second and third trimester and foetal weight. Rev Bras Ginecol Obstet. 2013;35(7):317-22.

12. Balla EA, Ahmed MS, Ayad CE, Ahmed AS. Prediction of foetal growth by measuring the placental thickness using ultrasonography. J Gynecol Obstet. 2014;2(2):26-31.

13. Warsof SL, Wolf P, Coulehan J, Queenan JT. Comparison of foetal weight estimation formulas with and without head measurements. Obstet Gynecol. 1986;67:569-73.

14. Roy M, Gajbe UL, Singh BR, Thute P. Morphometric measurement of foetal femur length for the prediction of gestational age in the second and third trimesters of pregnancy by ultrasonography. J Datta Meghe Inst Med Sci Univ. 2017;12:187-90.

Cite this article as: Goldy SJ, Victor SR, Oral BJ, Thangam A, Christopher U, Rose A. Placental thickness and its correlation with estimated foetal weight: a cross-sectional study in a tertiary care centre in South India. Int J Reprod Contracept Obstet Gynecol 2019;8:1347-54. 